\title{
Is the COVID-19 Pandemic a Supply or a Demand Shock?
}

Pedro Brinca, Assistant Professor of Economics, Nova School of Business and Economics, Lisbon Joao B. Duarte, Assistant Professor of Economics, Nova School of Business and Economics, Lisbon Miguel Faria-e-Castro, Economist

$\mathrm{n}$ response to the COVID-19 outbreak, public health authorities around the world implemented mitigation measures such as social distancing, which shut down entire sectors of the economy, especially those that involve interpersonal contact, such as restaurants and salons. While authorities have forced many such establishments to close, leaving many workers jobless, and issued stay-at home orders (so-called lockdowns), consumers also decreased their use of these services. ${ }^{1}$ Further, newly jobless workers reduced their consumption of all goods and services.
For this reason, most economists would agree that the pandemic combines aspects of both supply and demand shocks. A supply shock is anything that reduces the economy's capacity to produce goods and services, at given prices. Lockdown measures preventing workers from doing their jobs can be seen as a supply shock. A demand shock, on the other hand, reduces consumers' ability or willingness to purchase goods and services, at given prices. People avoiding restaurants for fear of contagion is an example of a demand shock. Additionally, as service sector workers

Figure 1

Shock Decomposition of the Growth of Hours Worked by Sector, March 2020
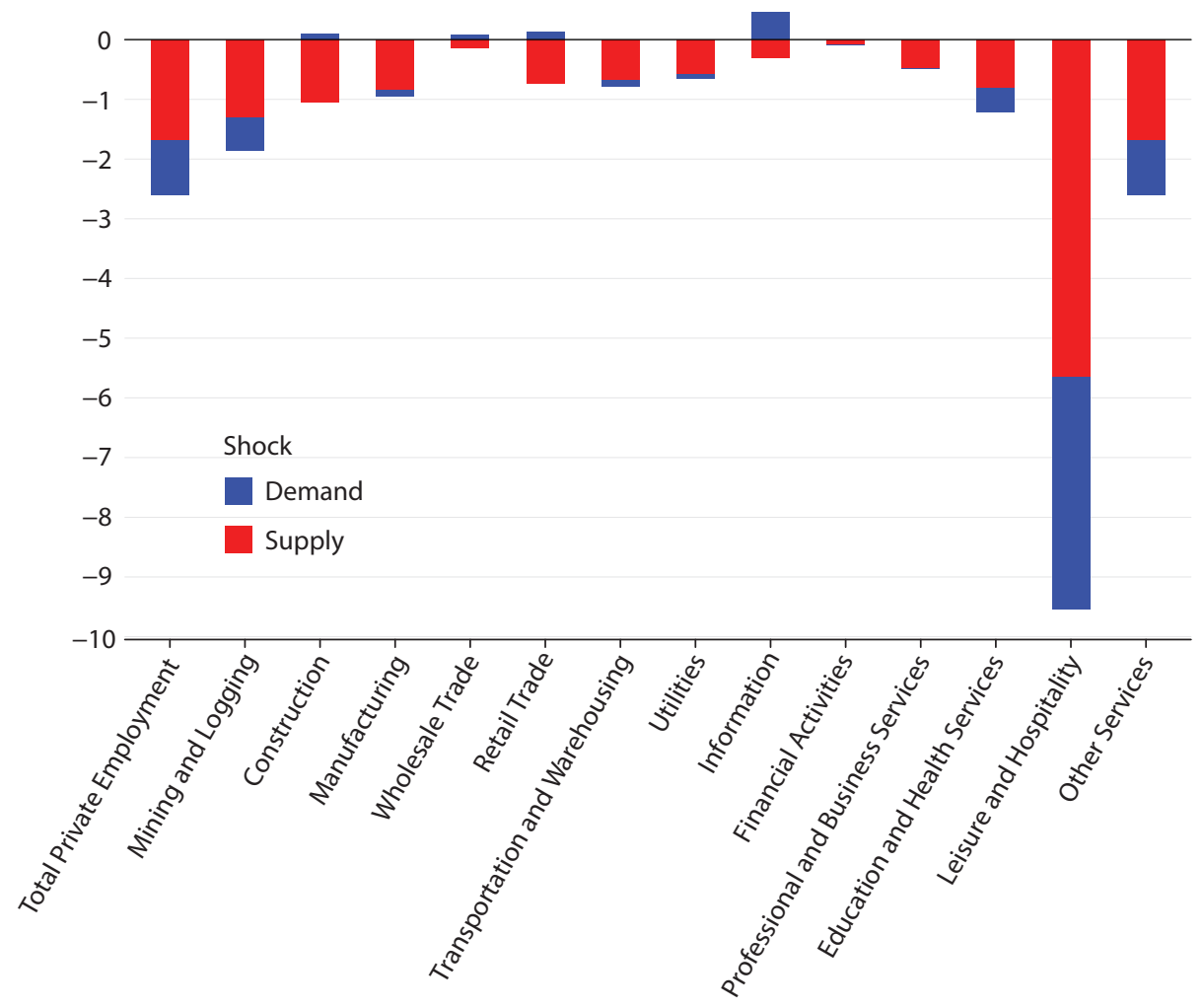

SOURCE: Brinca, Duarte, and Faria-e-Castro (2020). 
Figure 2

Shock Decomposition of the Growth of Hours Worked by Sector, April 2020

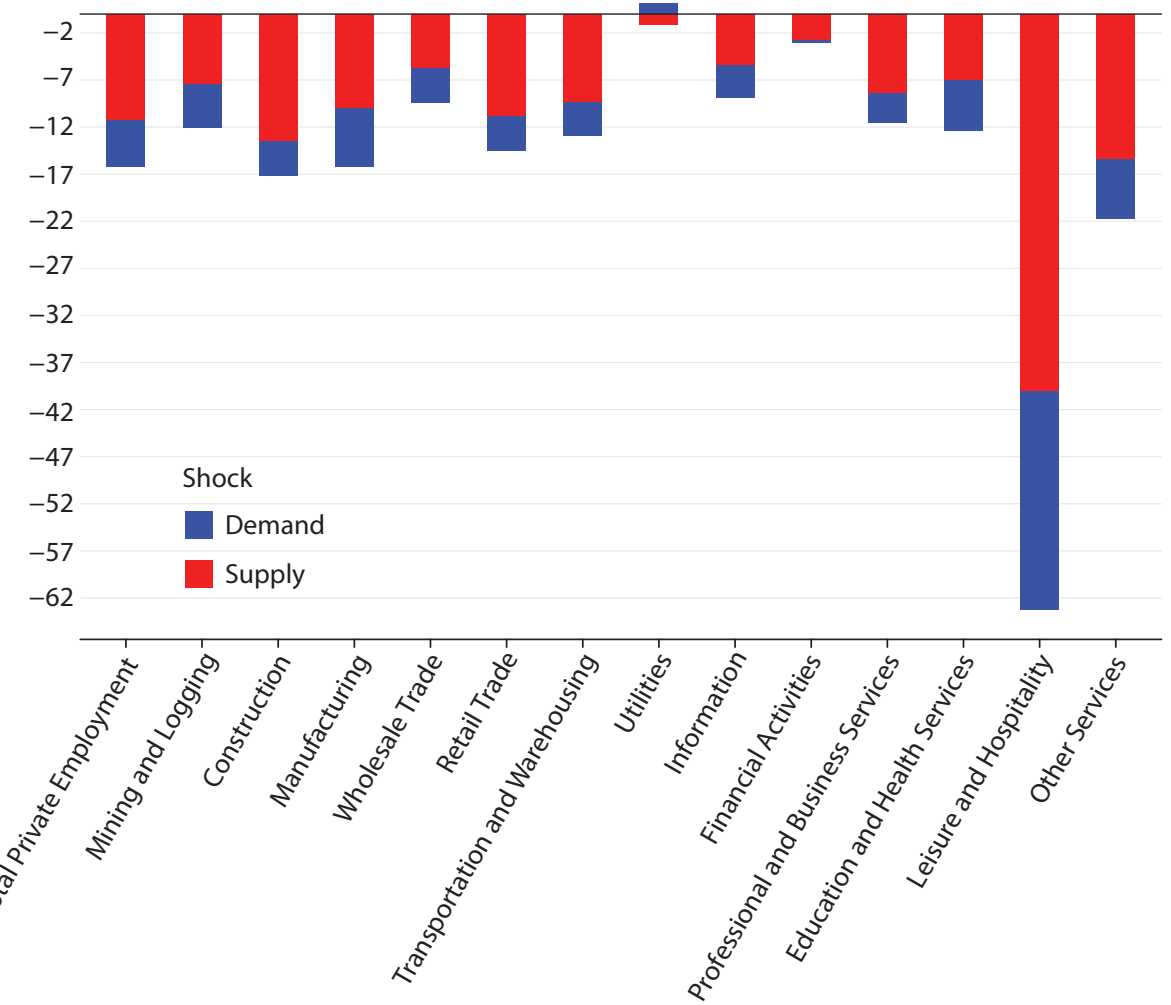

SOURCE: Brinca, Duarte, and Faria-e-Castro (2020).

lose their jobs and income, they stop purchasing all kinds of goods, such as cars and appliances, which can also be thought of as a sectoral demand shock.

Labor supply shocks likely account for most of the fall in hours worked.

Conventional monetary and fiscal policy can offset some types of aggregate demand shocks, but other policies may be more appropriate to counter supply shocks. Understanding whether supply or demand causes a particular shock is therefore very important for policy design. The government doesn't want to stimulate activity in certain service sectors because of concerns about further spreading COVID-19. The government could, however, stimulate sectors that are not part of the lockdown but are subject to aggregate shocks. This means that it is important to understand whether supply or demand shocks or both affect each sector.

In a recent paper (Brinca, Duarte, and Faria-e-Castro, 2020), we use data on U.S. hours worked and real wages to estimate labor demand and supply shocks for the aggre- gate economy and for different sectors. The following simple assumptions identify supply and demand shocks: If hours and wages (prices and quantities) move in the same direction, we assign a higher probability to those movements being caused by a demand shock. On the other hand, if hours and wages move in opposite directions, we assign a higher probability to a supply shock. ${ }^{2}$

Figure 1 plots the shock decomposition for March 2020, when the lockdown began, of the growth rate of hours worked by sector. The sum of the red and blue bars is the percentage point change in the growth rate of hours worked relative to its historical average; the size of the red bar relative to the blue bar shows how important supply shocks were relative to demand shocks in that sector. For example, for Total Private Employment (listed first), the growth rate of hours worked fell about 2.5 percent (nonannualized); supply shocks accounted for about two-thirds of that decline. By far the most-affected sector was Leisure and Hospitality, where the growth rate of hours worked fell by almost 10 percentage points. Again, supply played a slightly larger role than demand. While most sectors experienced negative supply shocks, some sectors experienced small positive demand shocks; for example, Retail Trade likely 
benefited as people stopped going to restaurants and started buying more groceries and cooking at home. The Information sector also benefited, likely due to increased interest in telecommuting.

Figure 2 repeats the exercise for April 2020, the first full month of the lockdown. For Total Private Employment, the growth rate of hours fell by almost 17 percentage points in April, about 10 times as much as in March. Again, supply shocks seemed to explain about two-thirds of the decrease for most sectors. Also, during this month, the positive demand shocks in sectors such as Retail and Information vanished-or even reversed.

All in all, our results suggest that labor supply shocks accounted for most of the fall in hours in March and April, but demand shocks were also important. In particular, there were significant demand shocks in sectors that should not be very directly affected by the lockdown, such as Manufacturing. This suggests that targeted stabilization policy could help assuage the effects of the current crisis.

\section{Notes}

${ }^{1}$ For example, a recent paper (Andersen et al., 2020) compares personal expenditures between Denmark, a country that imposed a lockdown, and Sweden, a country that did not, and finds that consumption expenditures fell in both countries by similar amounts.

2 This builds on work by Baumeister and Hamilton (2015).

\section{References}

Andersen, A.L.; Hansen, E.T.; Johannesen, N. and Sherdian, A. "Pandemic, Shutdown and Consumer Spending: Lessons from Scandinavian Policy Responses to COVID-19." 2020; arXiv:2005.04630.

Baumeister, C. and Hamilton, J. "Sign Restrictions, Structural Vector Autoregressions, and Useful Prior Information." Econometrica, 2015, 83(5), pp. 1963-99.

Brinca, P.; Duarte, J.B. and Faria-e-Castro, M. "Measuring Sectoral Supply and Demand Shocks during COVID-19." Working Paper 2020-011B, Federal Reserve Bank of St. Louis, 2020;

https://research.stlouisfed.org/wp/more/2020-011. 